\title{
Deuterium Retention and Out-gassing from Beryllium Oxide on Beryllium
}

\author{
J. Roth ${ }^{1}$, W.R. Wampler ${ }^{2}$, M. Oberkofler ${ }^{1, *}$, S. van Deusen ${ }^{2}$, S. Elgeti ${ }^{1}$ \\ ${ }^{1}$ Max-Planck-Institut für Plasmaphysik, Boltzmannstraße 2, D-85748 Garching, Germany \\ ${ }^{2}$ Sandia National Laboratories, Albuquerque NM 87185-1056, USA
}

\begin{abstract}
The desorption of $\mathrm{D}$ implanted into Be with a superficial oxide layer is studied. The implantation at different energies resulted in a strong variation of the fraction stopped within the oxide layer. Thermal desorption of $\mathrm{D}$ was subsequently performed, intermitted by nuclear reaction analysis for assessment of the $\mathrm{D}$ depth distributions and total retained amounts. For the conditions, where part of the $\mathrm{D}$ was deposited in the Be substrate, a sharp decrease of the retained amount of D occurs around $200{ }^{\circ} \mathrm{C}$. This is attributed to the release from metallic Be. Correspondingly, the $\mathrm{D}$ and $\mathrm{O}$ depth profiles show that above $200{ }^{\circ} \mathrm{C}$ the remaining $\mathrm{D}$ is only retained in the $\mathrm{BeO}$ layer. Apparently, the superficial $\mathrm{BeO}$ layer does not act as a diffusion barrier for $\mathrm{D}$ that is released from the metallic substrate. The retained amount of D deposited within the $\mathrm{BeO}$ layer decreases steadily and is not completely released at $350{ }^{\circ} \mathrm{C}$, the foreseen bake-out temperature in ITER.
\end{abstract}

*Corresponding author: Martin Oberkofler, martin.oberkofler@ipp.mpg.de, +498932991005 


\section{Introduction}

In ITER the first wall of the main plasma chamber will be covered with $\mathrm{Be}\left[{ }^{1}\right]$ in order to avoid risks connected to high central impurity radiation and to profit from the oxygen gettering capability of Be. Tritium retention in Be due to implantation is tolerable as the retention saturates within the ion range $\left[2,{ }^{2},{ }^{4},{ }^{6},{ }^{6}\right]$ without inward diffusion. However, the co-deposition of hydrogen isotopes together with eroded and re-deposited Be atoms dominates all other retention processes and limits the operational time when the critical tritium inventory of $700 \mathrm{~g}$ is reached $\left.{ }^{7}\right]$. The retention and release rates from co-deposited layers are influenced by the relation of incident Be,

$\mathrm{D}$ and $\mathrm{O}$ fluxes $\left[{ }^{8},{ }^{10},{ }^{10}\right]$. Also oxidation of the Be surfaces in the main chamber upon venting of the vacuum vessel can affect the release behaviour of hydrogen isotopes.

Therefore, the investigation of Be oxidation and its influence on hydrogen retention are of vital interest. Gulbransen and Andrew [ ${ }^{11}$ ] have examined the kinetics of Be oxidation by measuring the weight gain during heating in oxygen with a vacuum microbalance. They observed that at constant temperature the oxidation rate follows a parabolic time dependence indicating that diffusion of Be through the oxide is the rate determining process. A later experiment using ion beam analysis for detection of different oxygen isotopes $\left[{ }^{12}\right]$ could clearly verify the diffusion of Be through the superficial oxide layer as the rate limiting step for oxidation below temperatures of $680^{\circ} \mathrm{C}$.

In ITER out-gassing of the divertor cassettes up to $350{ }^{\circ} \mathrm{C}$ is is foreseen once the in-vessel limit of $700 \mathrm{~g}$ T is reached $\left[{ }^{13}\right]$. (Other possible T removal methods are Ion Cleaning Wall Conditioning and isotopic plasma exchange.) This thermal approach can be expected to be effective for removal of $\mathrm{T}$ from pure Be and clean co-deposited layers: It has been shown that $\mathrm{D}$ implanted into Be at high fluences is released in a sharp peak around $\left.180{ }^{\circ} \mathrm{C}^{2,6}\right]$. However, higher temperatures are necessary to remove hydrogen isotopes retained in oxidised beryllium, since the release from $\mathrm{BeO}$ occurs in a broad temperature range extending to above $700{ }^{\circ} \mathrm{C}\left[{ }^{6,14}\right]$. In this paper results are presented for $\mathrm{D}$ retention and thermal release after implantation at $\mathrm{keV}$ energies into $\mathrm{BeO}$ layers on $\mathrm{Be}$ with ion ranges partly exceeding the oxide thickness.

\section{Experiments}


The samples were vacuum hot pressed Be (S65C grade) from MaTecK Material GmbH, Jülich, with a composition of $99.5 \mathrm{wt} \% \mathrm{Be}, 0.4 \mathrm{wt} \% \mathrm{O}$ and $0.1 \mathrm{wt} \%$ other impurities. The sample size is $10 \times 10 \times 1 \mathrm{~mm}^{3}$ for samples $\mathrm{A}, \mathrm{B}$ and $\mathrm{D}$ while sample $\mathrm{C}$ is a disk of $15 \mathrm{~mm}$ in diameter and $0.3 \mathrm{~mm}$ thickness. The average grain size of the samples was $7.5 \mu \mathrm{m}$ and the surfaces were polished to mirror finish. For oxidation, the Be samples (except sample C) were heated in a vacuum furnace in pure oxygen gas at atmospheric pressure. The sample $\mathrm{C}$ was heated in air at $660{ }^{\circ} \mathrm{C}$ as described in $\left[{ }^{15}\right]$. After oxidation the samples were transferred to the High Current Ion Source of IPP Garching and implanted at temperatures below $50{ }^{\circ} \mathrm{C}$ with deuterium ions at energies per atom between 2 and $5 \mathrm{keV}$ to a fluence of $10^{22} \mathrm{~m}^{-2}$. The oxidation and exposure conditions for the various samples are summarised in Table 1. Analysis and thermal desorption was done in an ion beam analysis chamber at the $3.5 \mathrm{MeV}$ accelerator at Sandia National Laboratories Albuquerque. The chamber is equipped with detectors for Rutherford Backscattering Spectrometry (RBS) and Nuclear Reaction Analysis (NRA) at scattering angles of $175^{\circ}$ (annular detector) and $115^{\circ}$, respectively. The depth profiles of $\mathrm{Be}$ and $\mathrm{O}$ were obtained by RBS. NRA gave the amounts and depth profiles of $\mathrm{D}$. The analysis beam was ${ }^{3} \mathrm{He}$ at $1 \mathrm{MeV}$ for both RBS and NRA. The base pressure in the chamber was $4 \times 10^{-8} \mathrm{mbar}$ and did not exceed the $10^{-7}$ mbar range during ion beam analysis.

For in-situ thermal desorption studies the samples were tightly connected to a resistive heater capable of providing temperatures up to $900{ }^{\circ} \mathrm{C}$. The sample temperature was measured within $\pm 10{ }^{\circ} \mathrm{C}$ using a thermocouple pressed against the rear side of the sample. The total amounts and depth distributions of $\mathrm{D}$ in the $\mathrm{BeO} / \mathrm{Be}$ samples were determined before annealing and after annealing steps at $200,300,400,500$, and $600{ }^{\circ} \mathrm{C}$ for $10 \mathrm{~min}$.

\section{Results and discussion}

\subsection{Deuterium uptake:}

Table 1:

\begin{tabular}{|l|l|l|l|l|l|}
\hline $\begin{array}{l}\text { Sample } \\
\text { name }\end{array}$ & Oxidation & $\begin{array}{l}\text { BeO } \\
\text { thickness } \\
(\mathrm{nm})\end{array}$ & $\begin{array}{l}\text { Energy } \\
(\mathrm{keV} \text { per } \\
\text { atom })\end{array}$ & $\begin{array}{l}\text { Fluence } \\
\left(\mathrm{D} / \mathrm{m}^{2}\right)\end{array}$ & $\begin{array}{l}\text { TRIM range + } \\
\text { FWHM in BeO } \\
(\mathrm{nm})\end{array}$ \\
\hline $\mathrm{A}$ & in O2 & 50 & 5 & $10^{22}$ & 106 \\
\hline $\mathrm{B}$ & in O2 & 80 & 3 & $1.1 \times 10^{22}$ & 68 \\
\hline $\mathrm{C}$ & in air & 100 & 2 & $10^{22}$ & 45 \\
\hline $\mathrm{D}$ & native oxide & 10 & 2 & $10^{22}$ & $73(\mathrm{in} \mathrm{Be})$ \\
\hline \multicolumn{7}{|r}{3} \\
\hline
\end{tabular}


All implantations were performed at room temperature. The uptake of implanted D atoms as measured by NRA is shown in Fig. 1. The data points after implantation at 2, 3 and $5 \mathrm{keV} /$ atom were obtained in the present investigation. Data from previous investigations at lower energies $\left[{ }^{15}\right]$ were obtained using oxide thicknesses by far exceeding the ion range and are plotted in the same graph. The total retention at a given fluence of $1 \times 10^{22} \mathrm{D} / \mathrm{m}^{2}$ increases monotonically with the energy of the implanted D atoms. This is explained by the fact that at this fluence saturation of the $\mathrm{D}$ concentration up to the maximum ion range is reached in $\mathrm{Be}$ and $\mathrm{BeO}\left[{ }^{3},{ }^{16},{ }^{17},{ }^{18}\right]$. The associated saturation levels for $\mathrm{BeO}$ and $\mathrm{Be}$ are similar at about 10 to 15 at\% (cf. top graph in Fig. 2). Within this simple model (saturation with $\mathrm{D}$ up to the ion range) the retained amounts can be estimated from simulations with the Monte Carlo code TRIM [ $\left.{ }^{19}\right]$. In contrast, for the experiments in $\left[{ }^{15}\right]$ a comparison to TRIDYN calculations was mandatory because of the higher fluences and corresponding non negligible erosion, which could not be taken into account in a TRIM calculation. The ion ranges resulting from these calculations in units of $(\mathrm{Be}+\mathrm{O})$ atoms $/ \mathrm{m}^{2}$ are multiplied by a saturation concentration of 12 at\% to calculate the expected retained amounts of D. The value of 12 at\% was directly measured on sample A (see Fig. 2). On the other samples the measurement of the $\mathrm{D}$ depth profile is more difficult due to the lower implantation depth and the limited depth resolution of NRA. The value of 12 at\% agrees well with literature $\left[{ }^{17}\right]$ and is assumed to be valid also for the other three samples. The retained amounts estimated in this way are depicted in Fig. 1 (open symbols) together with the experimental data (full symbols).

For the special purpose of this study, also oxide layers close to and thinner than the ion penetration depth (sample A with $50 \mathrm{~nm} \mathrm{BeO}$ and sample B with $80 \mathrm{~nm} \mathrm{BeO}$, see Table 1) were produced in order to compare implantation into the oxide with implantation into the subjacent pure Be substrate and to assess the influence of the oxide layer on the release of D from the subjacent metal. Fig. 2 shows the depth profiles of $\mathrm{Be}, \mathrm{O}$ and $\mathrm{D}$ in the sample with a $\mathrm{BeO}$ layer thickness of $45 \mathrm{~nm}$ equivalent to $6.3 \times 10^{21} \mathrm{at} / \mathrm{m}^{2}$ (density of $\mathrm{BeO}: 1.45 \times 10^{29} \mathrm{at} / \mathrm{m}^{3}$ ). Profiles are shown after implantation with D at $5 \mathrm{keV} /$ atom and annealing stages of 200 and $300{ }^{\circ} \mathrm{C}$. Before annealing (Fig. 2a), the D profile extends over the oxide layer into the substrate up to a depth of $2 \times 10^{22} \mathrm{at} / \mathrm{m}^{2}$, equivalent to $138 \mathrm{~nm}$. The TRIM range calculation results in a maximum ion range of $106 \mathrm{~nm}$ for $\mathrm{BeO}$. This difference could be ascribed to the greater ion range in pure $\mathrm{Be}$ compared to $\mathrm{BeO}$, but it 
could also be explained by the limited NRA depth resolution, which is on the order of the step widths in shown the profiles

\subsection{Thermal release of deuterium}

The release of D was investigated by step-wise annealing to $200,300,400,500$ and $600{ }^{\circ} \mathrm{C}$. Both the reduction in total retained amounts and the development of the depth distributions were assessed. Fig. 3 shows the retained amounts for the different samples as a function of annealing temperature. After implantation into a Be-oxide thicker than the ion range (2 keV in Fig. 3) a slow continuous release is observed up to temperatures of $600{ }^{\circ} \mathrm{C}$. In cases of implantation beyond the $\mathrm{BeO}$ layer into the Be substrate a fast initial decrease of the retained amounts is seen at temperatures around $200-300{ }^{\circ} \mathrm{C}$, followed by a slow monotonous further release. Considering that TDS measurements have shown a sharp release maximum at roughly $180{ }^{\circ} \mathrm{C}\left[{ }^{6},{ }^{20}\right]$ it is possible that a small uncertainty of the temperature determination may be responsible for the fact that the decrease for the case of $5 \mathrm{keV}$ implantation occurs above $200{ }^{\circ} \mathrm{C}$ while it occurs below $200{ }^{\circ} \mathrm{C}$ for $3 \mathrm{keV}$. The different retained $\mathrm{D}$ amounts for $2 \mathrm{keV}$ implantation into Be compared to $\mathrm{BeO}$ indicate a higher saturation concentration in $\mathrm{BeO}$ than in $\mathrm{Be}$.

The D depth profiles of the sample implanted at $5 \mathrm{keV}$ after annealing to 200 and to $300{ }^{\circ} \mathrm{C}$ are shown in figures $2 \mathrm{~b}$ and $\mathrm{c}$. The highest energy was chosen for this comparison as it allows adequate depth resolution for $\mathrm{D}$ depth profiling. At $200{ }^{\circ} \mathrm{C}$ the part of implanted $\mathrm{D}$ which had been retained in the metallic Be substrate is essentially already released, while D implanted into the $\mathrm{BeO}$ layer is still retained. Further heating leads to a slow decrease of the D concentration within the $\mathrm{BeO}$ layer, to 6 at $\%$ at $300{ }^{\circ} \mathrm{C}$ (Fig. 2c) and $400{ }^{\circ} \mathrm{C}$, and still 2 at $\%$ at $500{ }^{\circ} \mathrm{C}$. Total release from $\mathrm{BeO}$ requires temperatures well above $500{ }^{\circ} \mathrm{C}$, in agreement with results from thermal desorption spectroscopy reported in $\left[{ }^{6}\right]$. Recent detailed computer simulations using TMAP-7 $\left[{ }^{21}\right]$ of the thermal desorption peaks from $\mathrm{D}$ in $\mathrm{BeO}$ on $\mathrm{Be}$ using activation energies from $\left[{ }^{22}\right]$ are consistent with the finding that an oxide layer does not have a strong influence on D desorption from Be.

In [6] it was shown that after implantation of $2 \times 10^{21} \mathrm{D} / \mathrm{m}^{2}$ into metallic Be almost $90 \%$ of the retained D are released within a narrow spike just below $200{ }^{\circ} \mathrm{C}$. In the present investigation only about half of the total amount released from metallic Be is released below $300^{\circ} \mathrm{C}$ (see Fig. 3). A 
possible explanation for the observed much stronger release tail up to $400{ }^{\circ} \mathrm{C}$ and above lies in the higher fluxes and fluences applied here compared to the previous measurements. They may be the cause for the observed stronger surface modifications, i.e. the blisters observed on the metallic Be after D exposure and annealing (see next chapter), which represent stronger trapping sites and thus increase the retention at higher temperatures.

\subsection{Surface modifications}

After implantation and thermal outgassing the surface topography has been investigated in a scanning electron microscope (SEM). No striking features could be found for any of the deliberately oxidized samples. However, the metallic Be sample was found to be covered by small circular blisters (Fig. 4). At the lower fluxes and fluences used in ref $\left[{ }^{6}\right]$ no such structures were observed. The blisters found here are untypical for hydrogen in metals. They rather resemble very much the blisters at metal surfaces that are observed after He implantation at similar ion energies

$\left[{ }^{23}\right]$. The microstructure produced by implantation of various materials with hydrogen isotopes depends on where precipitation occurs. For materials such as W or Ni implanted hydrogen precipitates into gas bubbles which nucleate at pre-existing defects such as grain boundaries typically far beyond the depth of implantation. For Be precipitation occurs predominantly within the implantation zone without deeper diffusion - similar to He implantation - and hence the depth where precipitation occurs is close to the ion range. In the present case this is about $70 \mathrm{~nm}$ (cf. Table 1). Coalescence of small bubbles at the end-of-range leads to blisters as seen in Fig 4.

At lower fluences (ref. $\left[{ }^{6}\right]$ ) no blistering occurred in Be and D was released at $180{ }^{\circ} \mathrm{C}$. The D retention in blisters and gas bubbles may be responsible for the higher release temperatures from metallic Be that were found in the present study.

\section{Conclusions}

D has been implanted into deliberately oxidised Be samples and subsequently outgassed by step-wise annealing. The observed temperature-dependent release and the evolution of the D depth profiles can be explained on the basis of previous TDS data $\left[{ }^{6}\right]$. D retained in the metallic Be substrate below the oxide is released already at temperatures below $200{ }^{\circ} \mathrm{C}$. Out-diffusing D atoms permeate through the saturated oxide layer $\left[{ }^{24}\right]$, which does not act as a diffusion barrier 
for D. As a consequence in ITER a superficial oxide layer, that could e.g. be formed on the Be plasma-facing components upon venting, does not prevent the thermal release of tritium from the Be substrate during outgassing at $350^{\circ} \mathrm{C}$. However, thick oxidised layers (that might e.g. be produced by co-deposition in the presence of oxygen due to a small air leak) can retain tritium at even higher concentrations than pure $\mathrm{Be}$, while thermal release requires temperatures well above $350{ }^{\circ} \mathrm{C}$.

In the case of metallic Be surface modifications similar to He blisters occurred in the present investigation, probably due to higher fluxes and fluences with respect to previous work. These blisters appear to present stronger retention sites leading to higher release temperatures. 


\section{Acknowledgements}

Sandia National Laboratories is a multi-program laboratory managed and operated by Sandia Corporation, a wholly owned subsidiary of Lockheed Martin Corporation, for the U.S. Department of Energy's National Nuclear Security Administration under contract DE-AC0494AL85000. Thanks are due to M. Baldwin for help in oxidation of sample C at PISCES. 
Figure captions:

Fig. 1: Retained D in $\mathrm{BeO}$ as function of energy per atom at a fluence of $1 \times 10^{22} \mathrm{D} / \mathrm{m}^{2}$. The data at low energies (insert) are taken from ref. $\left[{ }^{15}\right]$. The TRIM data shown for comparison are calculated with the assumption of a saturation concentration of 12 at\% $\mathrm{D}$ in $\mathrm{BeO}\left[{ }^{15}\right]$.

Fig. 2: Depth distribution of Be, $\mathrm{O}$ and $\mathrm{D}$ after implantation at $5 \mathrm{keV}$ (sample A) and subsequent annealing at 200 and $300{ }^{\circ} \mathrm{C}$.

Fig. 3: Total amounts of $\mathrm{D}$ retained in $\mathrm{Be}$ and $\mathrm{BeO}$ on $\mathrm{Be}$ with different thicknesses and implantation energies as function of annealing temperature. Data are obtained from protons and alpha particles resulting from the ${ }^{3} \mathrm{He}(\mathrm{D}, \mathrm{p})^{4} \mathrm{He}$ nuclear reaction.

Fig. 4: Blisters observed in the SEM after irradiation of Be with D at an ion energy of $2 \mathrm{keV}$ per atom. 
Fig. 1: Retained $\mathrm{D}$ in $\mathrm{BeO}$ as function of energy per atom at a fluence of $1 \times 10^{22} \mathrm{D} / \mathrm{m}^{2}$. The data at low energies (insert) are taken from ref. $\left[{ }^{15}\right]$. The TRIM data shown for comparison are calculated with the assumption of a saturation concentration of 12 at $\% \mathrm{D}$ in $\mathrm{BeO}\left[{ }^{15}\right]$.

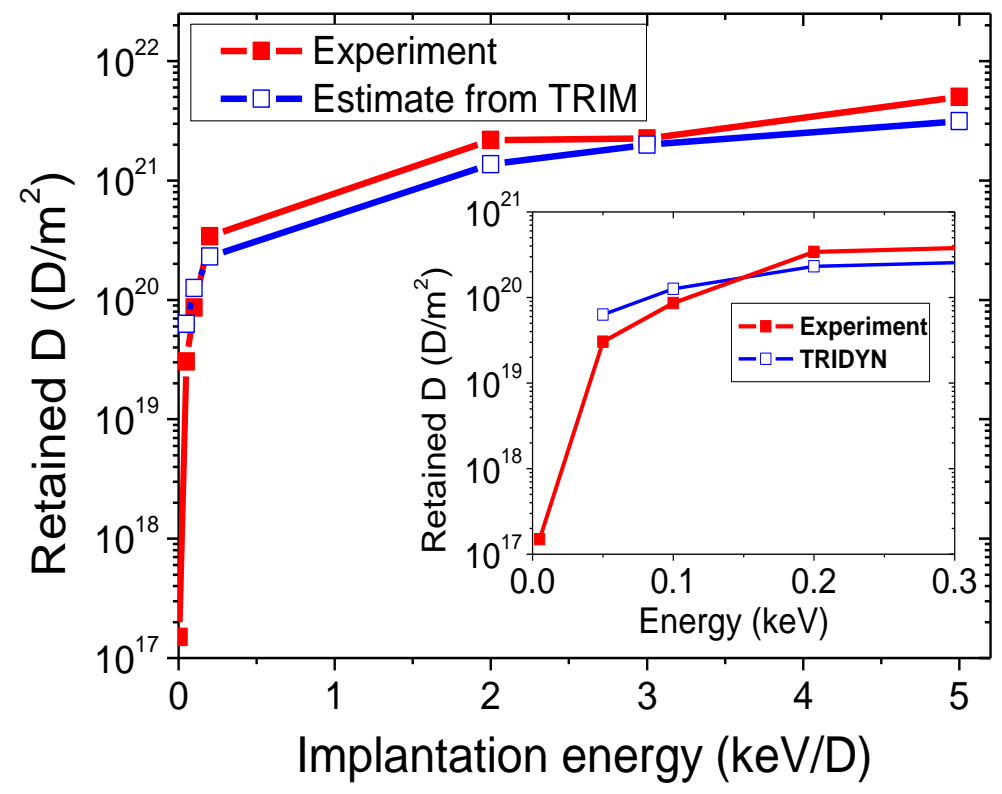


Fig. 2: Depth distribution of Be, $\mathrm{O}$ and $\mathrm{D}$ after implantation at $5 \mathrm{keV}$ (sample A) and subsequent annealing at 200 and $300{ }^{\circ} \mathrm{C}$.
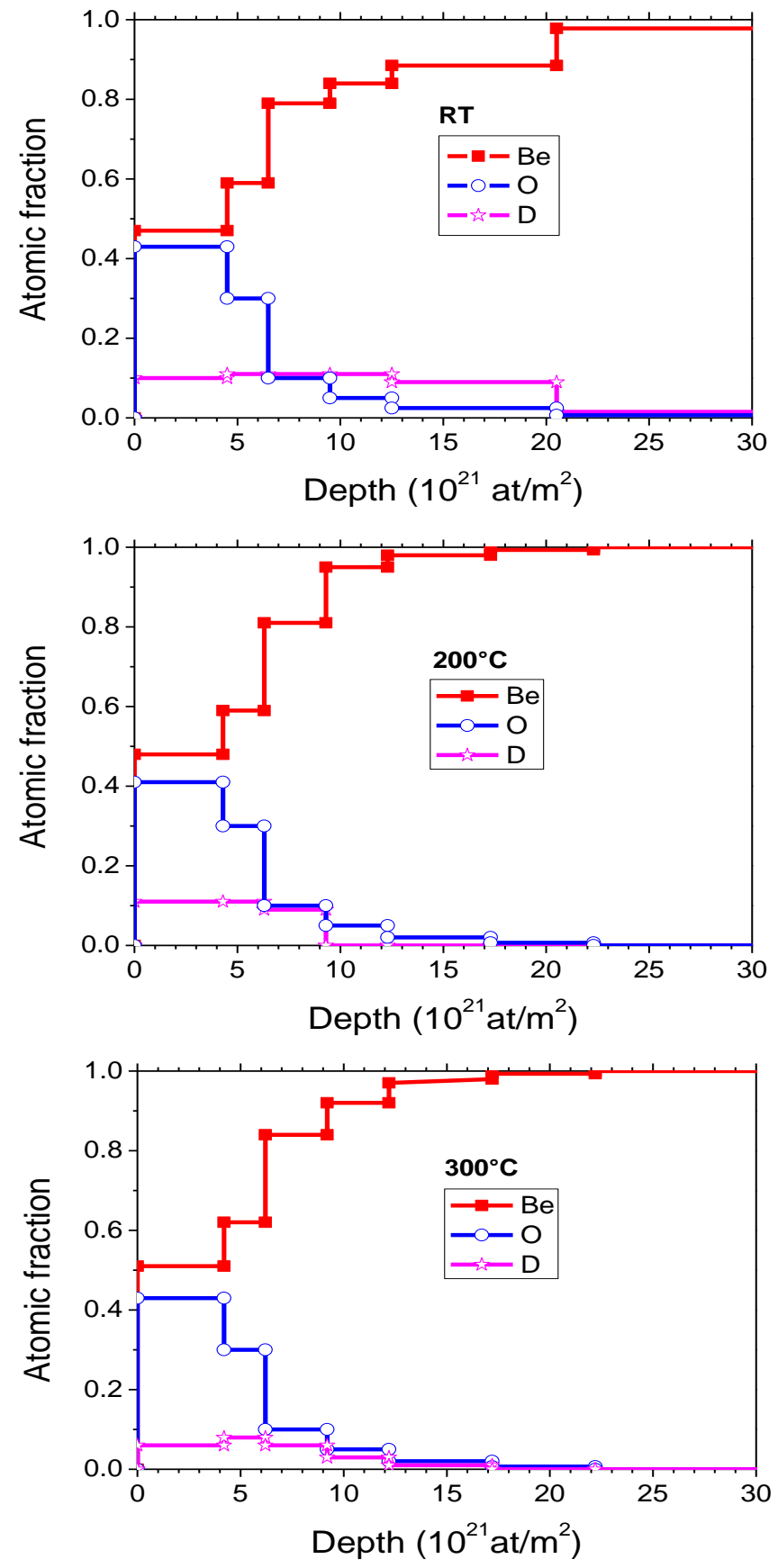
Fig. 3: Total amounts of retained in $\mathrm{Be}$ and $\mathrm{BeO}$ on $\mathrm{Be}$ with different thicknesses and implantation energies as function of annealing temperature. Data are obtained from protons and alpha particles resulting from the ${ }^{3} \mathrm{He}(\mathrm{D}, \mathrm{p})^{4} \mathrm{He}$ nuclear reaction.

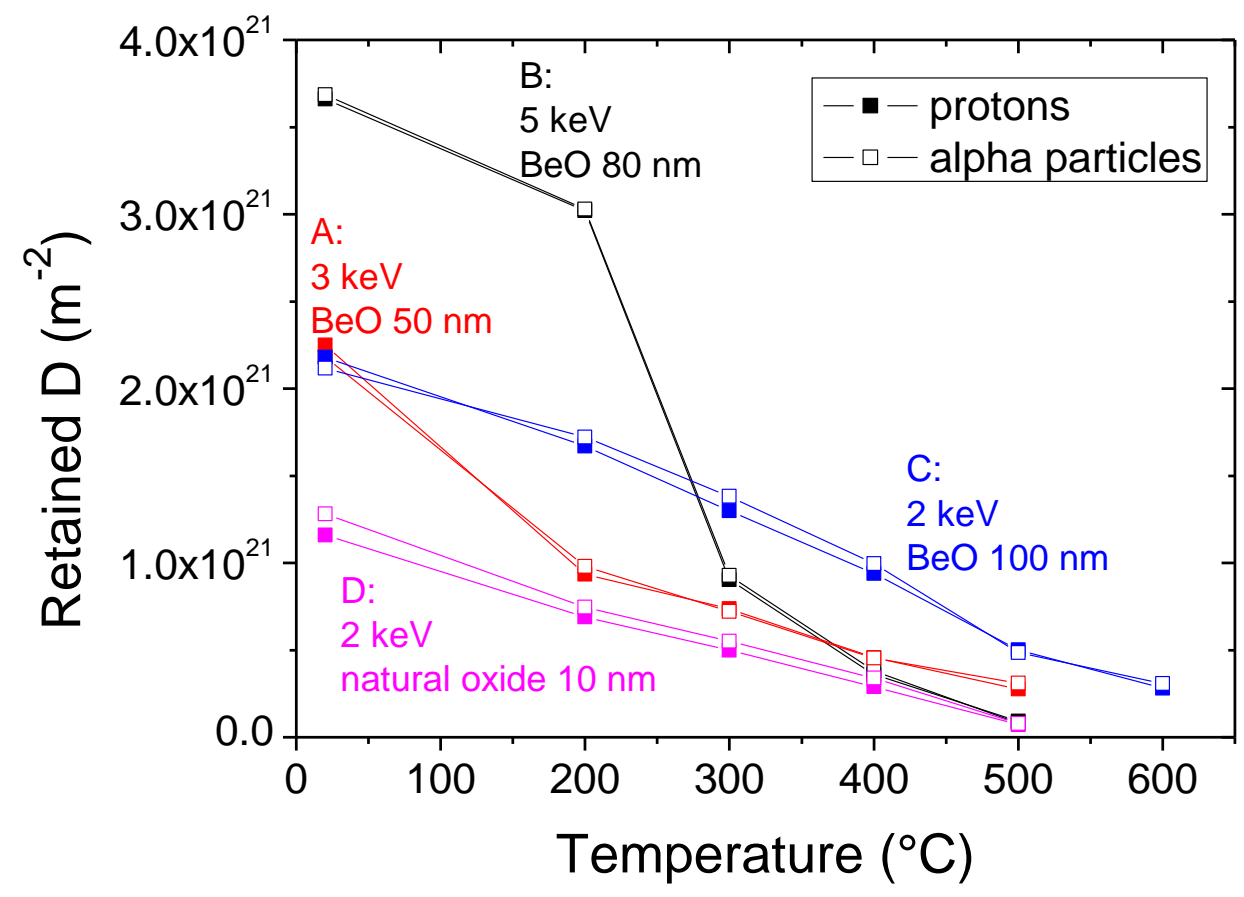


Fig. 4: Blisters observed in the SEM after irradiation of Be with D at an ion energy of $2 \mathrm{keV}$ per atom.
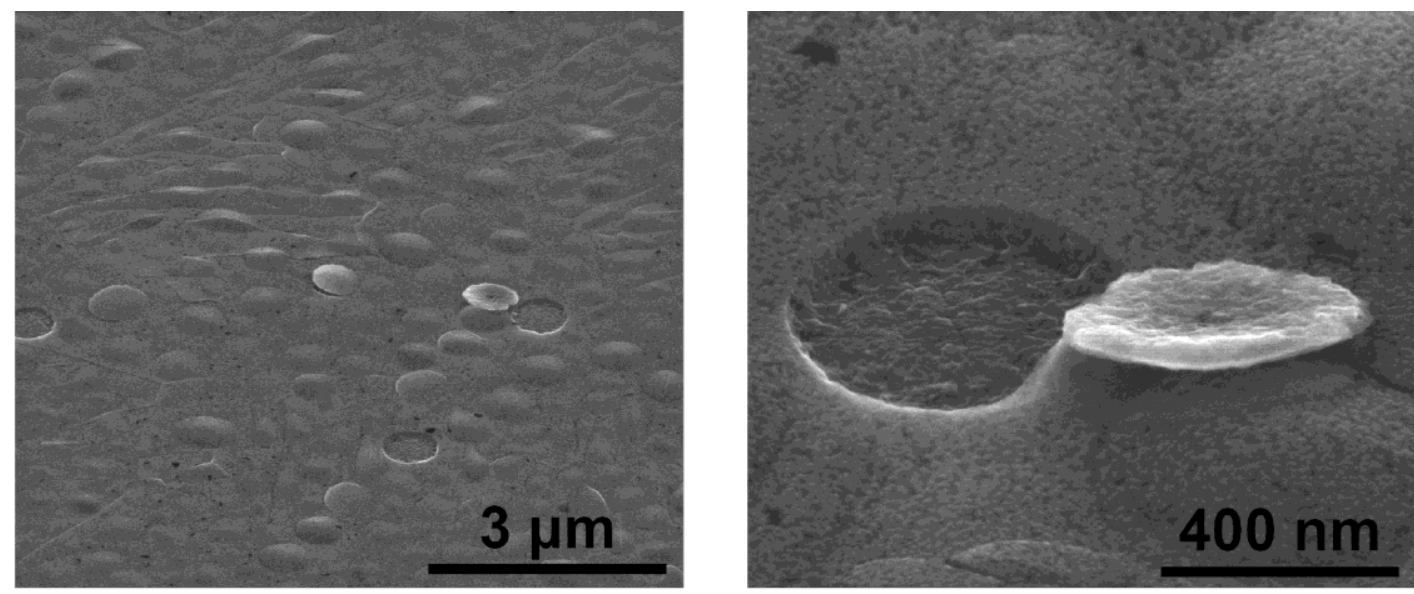


\section{References:}

$\left.{ }^{1}{ }^{]}\right]$A. Loarte, B. Lipschultz, A.S. Kukushkin, G.F. Matthews, P.C. Stangeby et al., "Chapter 4: Power and particle control", Nucl. Fusion 47 (2007) S203

$\left.{ }^{2}\right]$ M. Reinelt et al., New J. Phys. 11 (2009) 043023

$\left[{ }^{3}\right]$ R.A. Anderl, R.A. Causey, J.W. Davis, R.P. Doerner, G. Federici, A.A. Haasz, G.R. Longhurst, W.R. Wampler, K.L. Wilson, J. Nucl. Mater. 273 (1999) 1

$\left[{ }^{4}\right]$ W. Möller, B.M.U. Scherzer and J. Bohdansky, "Retention and release of deuterium implanted into beryllium” IPP-JET Report No. 26; (March 1985)

$\left.{ }^{5}\right]$ M. Reinelt, Ch. Linsmeier, J. Nucl. Mater. 390-391 (2009) 568

[ $\left.{ }^{6}\right]$ M. Oberkofler and Ch. Linsmeier, J. Nucl. Mater. 415 (2011) S724

$\left.{ }^{7}\right]$ J. Roth et al., J. Nucl. Mater. 390-391 (2009) 1

$\left[{ }^{8}\right]$ M. Mayer, J. Nucl. Mater. 240 (1997) 164

['] G. De Temmerman and R.P. Doerner, 2009 Nucl. Fusion 49042002

$\left[{ }^{10}\right]$ M. J. Baldwin, K. Schmid, R. P. Doerner, A. Wiltner, Ch. Linsmeier, J. Nucl. Mater. (2005) $337-339,590-594$

$\left[{ }^{11}\right]$ E.A. Gulbransen, K.F. Andrew, J. Electrochem. Soc. 97 (1960) 383.

$\left.{ }^{12}\right]$ J. Roth, W.R. Wampler, W. Jacob, J. Nucl. Mater. 250 (1997) 23

$\left[{ }^{13}\right]$ R.A. Pitts et al., Phys. Scr. T138 (2009) 014001

$\left[{ }^{14}\right]$ K. Sugiyama et al. J. Nucl. Mat. 415 (2011) S731-S734

$\left[{ }^{15}\right]$ J. Roth, R. Doerner, M. Baldwin, T. Dittmar, H. Xu, K. Sugiyama, M. Reinelt, Ch.

Linsmeier, M. Oberkofler, J. Nucl. Mater. 438 (2013) S1044

$\left.{ }^{16}\right]$ B.M.U. Scherzer, R.S. Blewer, R. Behrisch, R. Schulz, J. Roth, J. Borders, R. Langley, J. Nucl. Mater. 85-86 (1979) 1025

$\left[{ }^{17}\right]$ R. Behrisch, R.S. Blewer, J. Borders, R. Langley, J. Roth, B.M.U. Scherzer, R. Schulz, Radiation Effects 48 (1980) 221

$\left.{ }^{18}\right]$ M. Oberkofler et al., NIMB 269 (2011) 1266

$\left[{ }^{19}\right]$ J.P. Biersack and L.G. Haggmark, Nucl. Instrum. Meth. 174 (1980) 257

$\left[{ }^{20}\right]$ William R. Wampler, J. Nucl. Mater. 122\&123 (1984) 1598

$\left[{ }^{21}\right]$ M. Baldwin et al. JNM 438 (2013) S967

$\left.{ }^{22}\right]$ R.G. McCaulay-Newcombe et al., Fus.Eng.Des. 18 (1991) 419 
$\left[{ }^{23}\right]$ B.M.U. Scherzer, in "Sputtering by particle bombardment II", ed. R. Behrisch, Topics in Applied Physics (Springer, Berlin 1983) p. 271

$\left[{ }^{24}\right]$ W.R. Wampler, J. Nucl. Mater. 196\&198 (1992) 981 